\title{
RIF Artigos/Ensaios
}

\author{
DOI - 10.5212/RIF.v.18.i40.0011 \\ O audiovisual como arma de defesa indígena em tempos de \\ Covid-19
}

\author{
Mônica Panis Kaseker ${ }^{1}$ \\ Lucas Fernando Ribeiro ${ }^{2}$
}

\begin{abstract}
Submetido em: 10/05/2020
Aceito em: 26/05/2020
\end{abstract}

\section{RESUMO}

O artigo tem como proposta analisar a utilização do audiovisual nas mídias sociais como mecanismo de defesa e prevenção à Covid-19 junto às comunidades indígenas. A realização online do Acampamento Terra Livre, assim como debates e correntes de produção e de disseminação de vídeos de prevenção nas redes sociais indígenas marcaram a crise pandêmica no Brasil. A pesquisa resgata aspectos históricos sobre o papel das epidemias e moléstias na trajetória dos povos indígenas brasileiros, trazendo reflexões na perspectiva de autores indigenistas e indígenas sobre esta temática (OLIVEIRA; FREIRE, 2006; KOPENAWA; ALBERT, 2015; KRENAK, 2019). A partir da observação assistemática das redes sociais no período da pandemia, a pesquisa constata o fortalecimento do midiativismo indígena e a expansão da autorrepresentação pelo audiovisual.

\section{PALAVRAS-CHAVE}

Audiovisual; Mídias sociais; Midiativismo indígena.

\section{Audiovisual as a weapon for indigenous defense in Covid-19 times}

\begin{abstract}
This paper aims to analyze the use of audiovisual production in social media as a Covid-19 defense and prevention mechanism among indigenous communities. The online holding of the Camp Free Land, as well debates and the production and dissemination of prevention videos on indigenous social networks marked the pandemic crisis in Brazil. The research brings up some historical aspects of the role played by epidemics and diseases in the trajectory of Brazilian indigenous peoples, raising reflections on this theme from the perspective of both

\footnotetext{
${ }^{1}$ Jornalista formada pela PUCPR, com Mestrado e Doutorado em Sociologia pela UFPR, com estágio doutoral na UAM-X no México. Professora adjunta do curso de Jornalismo e do Mestrado em Comunicação da UEL. Correio eletrônico: mkaseker@gmail.com.

${ }^{2}$ Jornalista (UEL), mestrando em Comunicação pela UEL, bolsista da Capes. Correio eletrônico: lucasrib.7@gmail.com.
} 
non-indigenous and indigenous authors (OLIVEIRA; FREIRE, 2006; KOPENAWA; ALBERT, 2015; KRENAK, 2019). From the unsystematic observation of social media in Covid-19 times, this research notes the empowerment of indigenous media activism and the expansion of selfrepresentation through audiovisual.

\section{KEY-WORDS}

Audiovisual; Social media; Indigenous media activism.

\section{El audiovisual como arma de defesa indígena en tiempos de Covid-19}

\section{RESUMEN}

El artículo tiene como objetivo analizar el uso del audiovisual en las mídias sociales por las comunidades indígenas como un mecanismo de defensa y prevención para la Covid-19. La realización en línea del campamento Terra Livre, así como los debates y las corrientes de producción y difusión de videos de prevención en las redes sociales indígenas marcaron la crisis pandémica en Brasil. La investigación recupera aspectos históricos sobre el papel de las epidemias y enfermedades en la trayectoria de los pueblos indígenas brasileños, trayendo reflexiones desde la perspectiva de autores no indígenas e indígenas acerca del tema (OLIVEIRA; FREIRE, 2006; KOPENAWA; ALBERT, 2015; KRENAK, 2019). Con base en la observación asistemática de las redes sociales en el período de la pandemia, la investigación concluye que en la pandemia hay un desarrollo del activismo mediático indígena y la expansión de la autorrepresentación a través del audiovisual.

\section{PALABRAS-CLAVE}

Audiovisual; Mídias sociales; Activismo mediático indígena.

\section{Introdução}

As epidemias e moléstias foram uma das ameaças constantes à existência das populações indígenas desde a chegada dos europeus ao continente americano. As primeiras estimativas demográficas realizadas no território que atualmente nomeamos como Brasil apontavam para a existência de aproximadamente 2,4 milhões de indígenas nos primeiros anos após a chegada dos portugueses (OLIVEIRA; FREIRE, 2006). Dados do Instituto Brasileiro de Geografia e Estatística (IBGE, 2010) no último Censo apontavam para uma população de 896.917 pessoas, destes 324.834 vivendo em zonas urbanas. A redução não foi apenas numérica, mas também na variedade étnica presente no território, visto que muitos povos 


\section{RIF, Ponta Grossa/PR Volume 18, Número 40, p.183-198, Janeiro/Junho 2020}

foram extintos. Não somente as doenças, mas outras políticas de dominação articuladas como a violência, a doutrinação e a miscigenação programada foram responsáveis pela dizimação das populações indígenas ao longo dos últimos cinco séculos.

Este artigo tem como proposta analisar a utilização do audiovisual nas redes sociais como mecanismo de defesa e prevenção à Covid-19 junto às comunidades indígenas. Trata-se de um recorte específico de uma pesquisa mais ampla em andamento que investiga a produção audiovisual como articuladora de sentidos de identidade e interculturalidade, em especial sobre os indígenas brasileiros. Para este recorte particularmente, a pesquisa resgata aspectos históricos sobre o papel das epidemias e moléstias na trajetória dos povos indígenas brasileiros, trazendo reflexões na perspectiva de autores indigenistas e indígenas sobre esta temática, como Oliveira e Freire (2006), Kopenawa e Albert (2015) e Krenak (2019).

O midiativismo indígena e a expansão da autorrepresentação pelo audiovisual são abordados com base em autores como Araújo (2015), Di Felice e Perreira (2017). A partir da observação assistemática das mídias sociais no período da pandemia, foi realizado um mapeamento sobre o uso do audiovisual pelo movimento indígena, no qual se destaca a realização online do Acampamento Terra Livre, assim como debates e correntes de produção e de disseminação de vídeos de prevenção nas redes sociais indígenas.

\section{A pandemia da Covid-19 depois de tantas epidemias}

Desde os primeiros anos da colonização no território que atualmente conhecemos como Brasil, as populações indígenas têm sofrido com as epidemias trazidas pelos europeus. Inicialmente, o contágio de doenças como varíola, sarampo e tuberculose dizimavam grupos inteiros. Entre 1562 e 1565, a varíola matou mais de 30 mil indígenas na Bahia, trazendo consigo fome e desarticulação dos povos indígenas. Muitos não morriam, mas acabavam se deslocando de seus territórios originais fugindo das moléstias e da escravidão (OLIVEIRA; FREIRE, 2006, p. 23-24).

Krenak (2019, p. 34) lembra que no ciclo das navegações para a Ásia, África e América grande parte daqueles mundos desapareceu:

O simples contágio do encontro entre humanos daqui e de lá fez com que essa parte da população desaparecesse por um fenômeno que depois se chamou epidemia, uma mortandade de milhares e milhares de seres. Um sujeito que saía 


\section{RIF, Ponta Grossa/PR Volume 18, Número 40, p.183-198, Janeiro/Junho 2020}

da Europa e descia numa praia tropical largava um rastro de morte por onde passava. $O$ indivíduo não sabia que era uma peste ambulante, uma guerra bacteriológica em movimento, um fim de mundo; tampouco o sabiam as vítimas que eram contaminadas. Para os povos que receberam aquela visita e morreram, o fim do mundo foi no século XVI. Não estou liberando a responsabilidade e a gravidade de toda a máquina que moveu as conquistas coloniais, estou chamando atenção para o fato de que muitos eventos que aconteceram foram o desastre daquele tempo. Assim como nós estamos hoje vivendo o desastre do nosso tempo (...)

O desastre a que se referia o autor ainda antecedia a epidemia da Covid-19. Outro pensador indígena discorre amplamente sobre as epidemias e seus efeitos devastadores sobre os povos indígenas é Davi Kopenawa, narrando sob a perspectiva Yanomani. As epidemias Xawarari ou fumaças de metal, segundo o Xamã, vinham sempre logo em seguida dos primeiros contatos com os não indígenas. Em suas descrições sobre vários episódios nos quais presenciou o adoecimento e a morte de seus parentes, Kopenawa revela a constante desconfiança de que até os presentes entregues pelos brancos nos contatos amistosos estavam infectados. Em um dos episódios, ele conta que um chefe de inspetoria aspirava tomar uma mulher Yanomani para si. Como não obteve a permissão da família da moça, tornou-se vingativo e depois de ameaçá-los teria contaminado a comunidade Sina ta à qual pertenciam.

Alguns deles me contaram que, cada vez mais enfurecido, ele enterrou perto da casa, durante a noite, uma caixa de metal contendo uma poderosa fumaça de epidemia. No dia seguinte, o calor do sol foi intenso e a caixa esquentou embaixo da terra. Após algum tempo, o veneno fez explodir a tampa e deixou escapar uma fumaça espessa que invadiu tudo. (KOPENAWA; ALBERT, 2015, p. 248-249).

O sogro de Davi Kopenawa descreveu o mesmo episódio a ele como sendo uma explosão provocada pelo chefe da inspetoria. Mas de qualquer forma, pouco depois de sua partida, as mortes começaram. O Xamã descreve a doença de forma dramática, não era simplesmente uma tosse, mas havia febre, coceiras insuportáveis e morte rápida: "Não demorou para haver cadáveres por todos os lados na casa de Sina Ta, tombados no chão ou encolhidos em suas redes. Muitos também morreram subitamente nas roças, na floresta ou na beira do rio" (KOPENAWA; ALBERT, 2015, p. 249). Dessa forma, os Yanomamis perderam muitos de seus velhos Xamãs. Sobreviveram aqueles que ao perceber a mortandade fugiram para longe. No caso dos Yanomamis, que permaneceram isolados por muito tempo, a 


\section{RIF, Ponta Grossa/PR Volume 18, Número 40, p.183-198, Janeiro/Junho 2020}

escravidão e as epidemias de sarampo, gripe e coqueluche começaram em meados do Século XVIII e se acentuaram a partir dos Anos 1940. A partir da década de 1970, com a chegada do garimpo e da exploração agrícola, foi a vez do alastramento da malária e das infecções respiratórias que mataram 13\% da população Yanomami no Brasil (KOPENAWA; ALBERT, 2015 , p. 559-562).

O que inicialmente aconteceu como um efeito colateral natural pelo contato entre europeus e os povos originários, tornou-se uma ação proposital ao longo da história. De fato, vírus da varíola e do sarampo foram utilizados como armas biológicas para o extermínio das populações indígenas no Brasil no século XIX, conforme já foi comprovado em alguns estudos antropológicos. Um dos casos ocorreu no Sul do Maranhão, em uma contaminação de varíola provocada por fazendeiros que eram contra os índios Timbira, quais eram vistos como um atraso à expansão da criação de gado. Em Santa Catarina e no Paraná, final do século XIX, roupas infectadas com vírus de varíola e sarampo eram deixadas para que os índios Xokleng e Kaingang se contaminassem. Os Botocudos, no vale do Rio Doce, também foram atacados desta forma (BLECHER, 2001).

No Brasil, assim como no caso da gripe espanhola em 1918 e na pandemia do H1N1 em 2009, a Covid-19 expõe a população em geral ao risco de morte. Ao longo desse período de pouco mais de 100 anos, intensificou-se a movimentação das pessoas com o desenvolvimento e a facilidade de transporte aéreo e terrestre, o que potencializou ainda mais o contágio. No entanto, a fragilidade das populações indígenas é sempre maior. Em 2009, na pandemia do H1N1, a Organização Mundial da Saúde (OMS) declarou que o risco de morte para a população indígena era de quatro a cinco vezes maiores em relação à população em geral (FONTES; THENÓRIO, 2009). Também em 2020, a maior incidência de contágio e mortalidade se deu em estados com predominância étnica indígena, particularmente no Estado do Amazonas (CONTAMINAÇÃO, 2020).

Os povos indígenas brasileiros, diante de todos os ataques e dificuldades enfrentados na convivência e interação com os não indígenas, ao longo dos últimos 520 anos, encontrou renovadas formas de existir e resistir.

O contato dos povos indígenas com os invasores coloniais - portugueses, franceses, holandeses etc. - não pode ser reduzido ao binômio extermínio e mestiçagem. Desde as primeiras relações de escambo (MARCHANT, 1980), 


\title{
RIF, Ponta Grossa/PR Volume 18, Número 40, p.183-198, Janeiro/Junho 2020
}

passando pelas inúmeras alianças guerreiras até o desespero causado pelas epidemias de varíola, cada povo indígena reagiu a todos os contatos a partir do seu próprio dinamismo e criatividade. (OLIVEIRA; FREIRE, 2006, p. 51).

Mais recentemente, pode-se mencionar que $o$ ingresso dos indígenas nas universidades, assim como no cenário político e eleitoral são exemplos dessas formas dinâmicas e criativas de se movimentar. A presença indígena na comunicação midiática é outro fenômeno em expansão neste início do século XXI, conforme abordaremos a seguir.

\section{A autorrepresentação e o uso do audiovisual}

A visibilidade e representatividade indígena no espectro político brasileiro começou no final do regime militar, com a criação de um movimento indígena mais organizado e centrado em suas reivindicações, a participação em foros internacionais - como o IV Tribunal Russel, em 1980, na Holanda -, a articulação de líderes indígenas que ganharam repercussão internacional, além da eleição de Mário Juruna, indígena Xavante, como deputado federal pelo Rio de Janeiro (1982-1986).

Com a forte organização política desses líderes e a visibilidade das reivindicações por eles demandadas, houve também uma reação negativa por parte de latifundiários, que viam agora os indígenas também como inimigos políticos. A imprensa, muitas vezes coagida pela economia do agronegócio, ainda endossa o discurso desses latifundiários desqualificando a luta por demarcação e a existência dos territórios indígenas (BITTENCOURT, 2019; LIMA, 2019). Atualmente, o reconhecimento dos direitos constitucionais e a presença ainda mais acentuada do sujeito indígena no cenário político global contribuem para a busca por suas raízes étnicas, culturais e religiosas, fortalecendo esses vínculos. E ainda: as demandas e propostas, assim como suas culturas, agora são faladas de dentro das comunidades, a partir das Etnomídias.

\begin{abstract}
Etnomídia é comunicar expressando sua identidade étnica para que exista um real empoderamento na apropriação das novas tecnologias pelos povos e culturas que a usam como ferramenta, fugindo da colonização audiovisual ou midiática dos formatos de mídia padronizados pelo pensamento ocidental, apresenta uma natureza contra hegemônica. (TUPINAMBÁ MACHADO, 2020)
\end{abstract}

Nesse sentindo, a cultura tradicional indígena é traduzida para o contexto da cultura digital por meio das Etnomídias. Para Canevacci (2015) a autorrepresentação foi uma virada 


\section{RIF, Ponta Grossa/PR Volume 18, Número 40, p.183-198, Janeiro/Junho 2020}

epistemológica, na qual os sujeitos indígenas afirmam o direito e desejo de representar a si mesmos. A partir da autorrepresentatividade, as Etnomídias contribuem para o fortalecimento da identidade cultural, assim como agem de forma a corroborar com a visibilidade do movimento indígena em meio à globalização.

O projeto Vídeo nas Aldeias (VNA), idealizado pelo indigenista Vincent Carelli no final da década de 1980, foi um dos incentivadores da autorrepresentação por meio do audiovisual - uma vez que passou a estimular que o cotidiano indígena fosse registrado pela perspectiva dos próprios indígenas, sendo eles os produtores e personagens de suas narrativas (ARAÚJO, 2015). Na atualidade, esse fenômeno se dá no contexto da Etnomídia, uma vez que criam seus próprios conteúdos em "um processo vivo que adquire um significado cosmológico para as culturas indígenas" (TUPINAMBÁ apud RIBEIRO; KASEKER, 2018).

Assim como o VNA, outras iniciativas audiovisuais também foram surgindo e, consequentemente, ampliando as reinvindicações e expandindo a visibilidade do movimento indígena e da autoimagem criada nessas narrativas. O exemplo disso são iniciativas mais recentes como o caso da Rádio Yandê que, ao atuar principalmente nas redes sociais, expande seus conteúdos para outros formatos, além do sonoro (a Yandê atua de forma categórica em lives e vídeos denunciativos). Também foi surgindo a presença de influenciadores digitais indígenas, como o caso do indígena Xavante Cristian Wari'u, que em seu canal do YouTube busca explicar, no intuito de descolonizar, a realidade indígena na atualidade. Menciona-se ainda, a iniciativa da Comissão Universidade para os Índios (CUIA) da Universidade Estadual de Londrina (UEL), junto ao Ciclo Intercultural de Iniciação Acadêmica, de produção de vídeos autobiográficos sobre os estudantes indígenas recém-ingressos na universidade que buscam refletir sobre a identidade étnico-comunitária indígena a partir da utilização do audiovisual (RIBEIRO; KASEKER, 2019).

No entendimento de Di Felice e Pereira (2017), essas narrativas audiovisuais, além da autorrepresentação - no sentido de dar voz e visibilidade ao movimento indígena na esfera pública, permitem a expansão de seus territórios e ecossistemas a partir da conexão com outros povos e outros contextos culturais, reelaborando os conceitos de espaço, técnica, 


\section{RIF, Ponta Grossa/PR Volume 18, Número 40, p.183-198, Janeiro/Junho 2020}

natureza e sociedade, e propiciando novas dimensões habitativas ${ }^{3}$ desses povos. Como será descrito a seguir: os povos indígenas passam a ocupar as redes e a demarcar as telas.

\section{A abordagem da Covid-19 pelos povos indígenas nas redes sociais}

Ailton Krenak, ambientalista e escritor indígena, no livro $O$ amanhã não está à venda (2020), faz a reflexão de como "explicar a uma pessoa que está fechada há um mês em um apartamento numa grande metrópole o que é o meu isolamento?", ao expor que os povos indígenas já vivem isolados há muito tempo na história brasileira. E a forma encontrada por indígenas de todo o Brasil de expor esse 'isolamento histórico' e, consequentemente, as vulnerabilidades vivenciadas em tempos de pandemia foi justamente de, mais ainda, ocupar as redes sociais.

Nos últimos anos os indígenas vêm ocupando as redes para denunciar a expropriação de seus territórios por garimpeiros, grileiros e madeireiros, reivindicar a demarcação de terras, e outros direitos previstos na Constituição Federal de 1988. Agora foi a vez de unir essas pautas reivindicatórias junto à situação pandêmica em que o mundo se encontra com o novo coronavírus, uma vez que os povos indígenas se apresentam vulneráveis à Covid-19 (OLIVEIRA et. al., 2020). Outro ponto da vulnerabilidade social como fator primordial da disseminação da Covid-19, foi apresentado em um estudo da Fiocruz e da Fundação Getúlio Vargas (FGV), e concluiu que "as microrregiões com maior vulnerabilidade estão na região norte e nordeste" (CODEÇO et. al., 2020). E é, justamente, na região norte do Brasil que se concentra o maior risco de contágio nas Terras Indígenas, como apontado pelo Mapa de Vulnerabilidade nas Terras Indígenas a COVID-19 (INSTITUTO SOCIOAMBIENTAL, 2020).

Com o agravamento da situação em todo o país ${ }^{4}$, as próprias comunidades, junto aos movimentos indígenas de todo o país, começaram a se organizar nas redes virtuais para denunciar e reivindicar mais atenção do Estado para a população indígena que vive com "limitações relacionadas com a assistência médica e logística de transporte de enfermos" (OLIVEIRA et. al., 2020), além de expor os embates enfrentados pelas comunidades indígenas

\footnotetext{
${ }^{3} \mathrm{O}$ termo se refere às teorizações que relacionam a forma de habitar indígena com a ideia de um habitar comunicativo indígena na internet. Ver Di Felice; Pereira (2017).

${ }^{4}$ Em pouco mais de dois meses - 26 de fevereiro a 5 de maio de 2020 - o Brasil saltou de 1 para 114 mil casos de Covid-19, de acordo com o Ministério da Saúde. Disponível em: https://covid.saude.gov.br/.
} 


\section{RIF, Ponta Grossa/PR Volume 18, Número 40, p.183-198, Janeiro/Junho 2020}

no que diz respeito ao desmatamento e garimpos ilegais, que prejudicam a sobrevivência dos povos indígenas e são entendidos por eles também como problemas de saúde pública.

Como exemplo da utilização das redes sociais como espaço de mobilização e luta do movimento indígena em tempos de pandemia, está a realização online da 16a edição do Acampamento Terra Livre 2020 (ATL-2020) ${ }^{5}$, maior encontro dos povos indígenas do Brasil, entre os dias 27 e 30 de abril. Foi a primeira vez que o encontro foi realizado online, justamente para evitar a aglomeração de pessoas e o contágio da Covid-19, na Esplanada dos Ministérios, em Brasília (DF), como comumente acontecia durante as edições anteriores do encontro. A transmissão do evento foi realizada nos canais da Articulação dos Povos Indígenas do Brasil (APIB) - site, YouTube, Instagram e Facebook - e conectou indígenas de vários lugares do Brasil.

O ATL 2020 teve como resultado quantitativo o número de 39 vídeos reproduzidos ao vivo que ainda constam no Facebook da APIB. Desse montante, 23 eram de mesas de discussões, seguindo a programação divulgada pela APIB, tratando de diversos temas, como: demarcação, saúde - principalmente sobre a Covid-19 -, educação, visibilidade LGBTQI+, participação da mulher indígena, preconceito e estereótipos, arte indígena entre outros temas. As lives tiveram de quatro mil a 28 mil visualizações, de acordo com a estimativa do Facebook da APIB. Porém, esse número pode ser maior, se considerado que as lives também foram transmitidas por outros movimentos, como a Mídia Índia, Conselho Indigenista Missionário (Cimi) entre outros.

O lema do ATL 2020 foi "Ocupando as redes e demarcando telas" (Figura 1), denotando que a luta indígena estava se utilizando de novas ferramentas como armas para reivindicar os direitos dos povos indígenas. "Além de lutar para demarcar as terras, agora também estamos lutando para demarcar as telas. Temos que utilizar as novas tecnologias para fortalecer a nossa luta e é isso que estamos fazendo nesse Acampamento Terra Livre",

\footnotetext{
${ }^{5}$ O Acampamento Terra Livre (ATL) teve sua primeira edição realizada em abril de 2005 e é considerado a maior mobilização indígena do país. O ATL reúne, desde o início, milhares de lideranças indígenas de todas as regiões do Brasil, na Esplanada dos Ministérios, em Brasília (DF), e é coordenado pelos dirigentes das organizações indígenas regionais que compõe a Articulação dos Povos Indígenas do Brasil (APIB). "O ATL permite o intercâmbio de realidades de realidades e experiências tão distintas, a identificação dos problemas comuns, a definição das principais demandas e reivindicações, e a deliberação sobre os eixos programáticos e ações prioritárias da APIB" (ARTICULAÇÃO DOS POVOS INDÍGENAS DO BRASIL, 2020). Disponível em: http://apib.info/apib/.
} 
afirmou a líder indígena Sônia Guajajara, da etnia Guajajara, durante o primeiro dia de transmissão do evento.

Figura 1 - Logo do Acampamento Terra Livre 2020

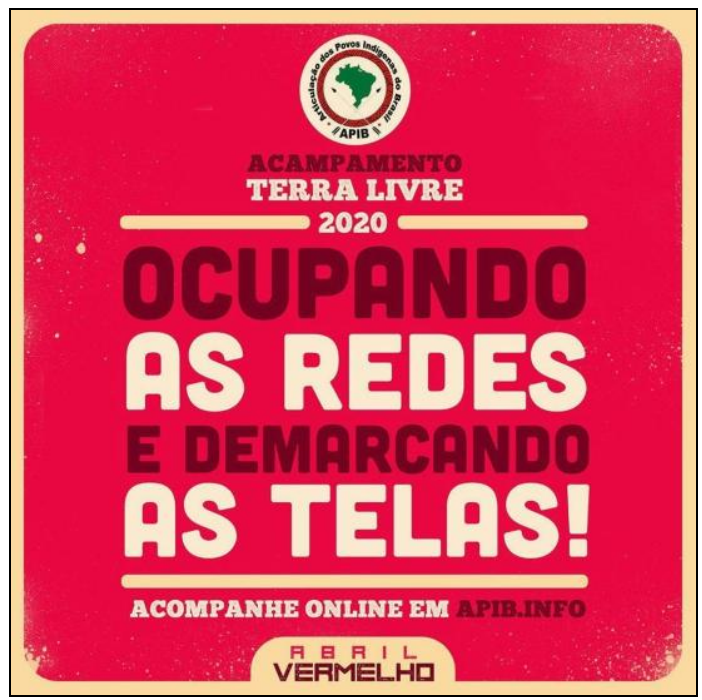

Fonte: Instagram/APIB

A partir do lema do ATL 2020, houve uma expansão do uso de conteúdos audiovisuais nas redes sociais por parte dos movimentos indígenas durante a pandemia. Além de conteúdos audiovisuais, o uso de hashtags que visam conscientizar as comunidades e contribuir para o enfrentamento da Covid-19, como por exemplo as hashtags: \#FicaNaAldeia em alusão à \#FicaEmCasa, \#UsaMáscaraParente, \#ContraAtaquelndígena, esta última utilizada em publicações de cunho denunciativo sobre as violações de direitos e descaso durante a pandemia. A iniciativa se deu a partir da Rádio Yandê, que pedia que os próprios indígenas gravassem com seus celulares os ataques e compartilhassem em suas redes sociais, conforme Figura 2. Outras hashtags foram \#AbrillndígenaLive, como referência ao ATL 2020 online, e \#ALutaNãoPara, denotando que mesmo com a pandemia, o movimento indígena e as reivindicações indígenas não pararam, assim como as ameaças de desmatamento e garimpo ilegais em seus territórios continuaram neste período (FELLET, 2020). 
Figura 2 - Campanha denunciativa sobre violações de direitos indígenas durante a pandemia

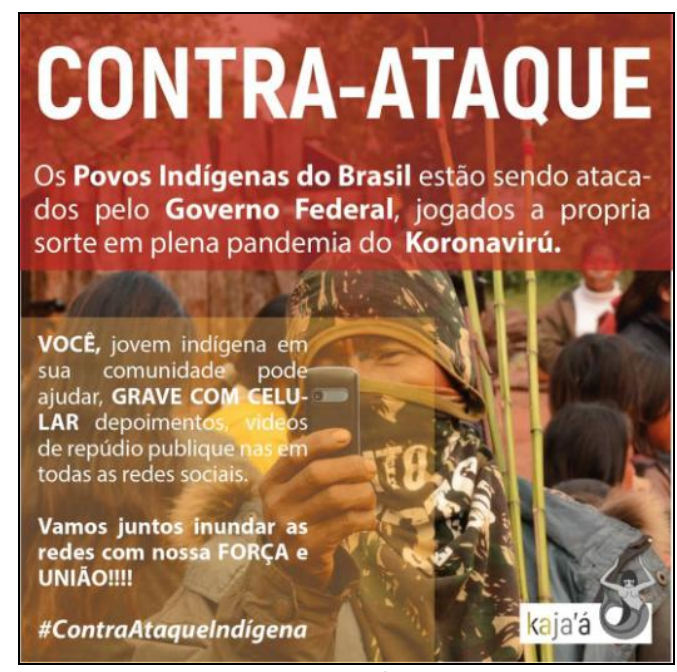

Fonte: Instagram/Rádio Yandê

Quanto à utilização do audiovisual, toma-se como exemplo os vídeos de lideranças indígenas dando seus recados para suas comunidades a respeito da importância do isolamento social e do cuidado consigo e com os demais nas aldeias (Figura 3). Os vídeos reforçam a necessidade de manter o distanciamento social para conter o avanço da Covid-19, principalmente dentro das aldeias - consideradas regiões de vulnerabilidade, e alertando para os cuidados que os indígenas devem ter durante a pandemia, especialmente nas semanas consideradas com maior probabilidade de contágio da doença. Ainda, os vídeos foram gravados nos idiomas indígenas, o que contribui para o entendimento de todos nas comunidades das etnias, principalmente os mais velhos.

Figura 3 - Zuleica Tiago, da etnia Terena, fala sobre o enfrentamento da Covid-19

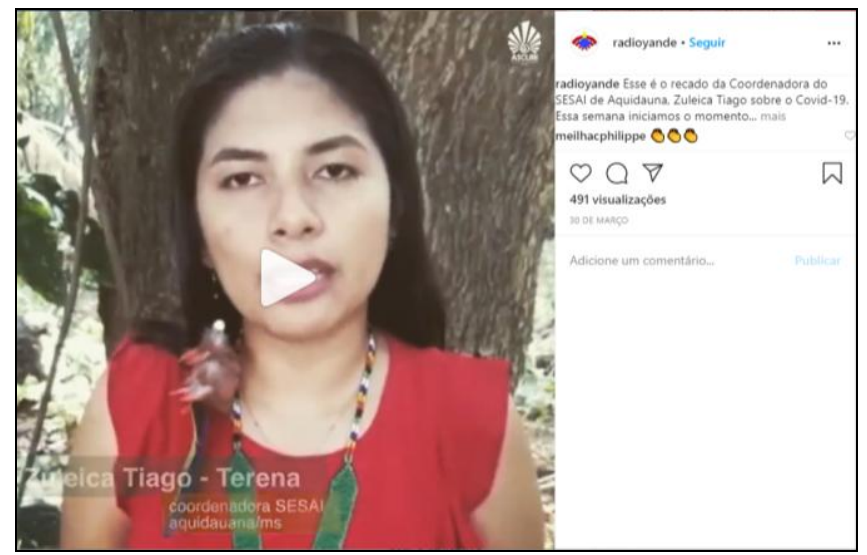

Fonte: Instagram/Rádio Yandê 


\section{RIF, Ponta Grossa/PR Volume 18, Número 40, p.183-198, Janeiro/Junho 2020}

Nessa mesma linha de abordagem, os estudantes universitários indígenas do Paraná promoveram uma corrente de produções de vídeos domésticos gravados com seus celulares. A cada publicação eles desafiavam mais três indígenas ou apoiadores da causa indígena a produzir seu próprio vídeo de orientações e alerta contra a Covid-19. A criatividade foi notável, para ensinar a lavar as mãos ou utilizar as máscaras adequadamente, brincavam com o certo e o errado nas imagens, e utilizavam adereços e elementos comunicativos étnicos como cocares, pinturas no rosto, músicas tradicionais, maracás para marcar a passagem de uma cena a outra, entre outros. Os vídeos mostraram identidades indígenas atualizadas, confirmando o caráter híbrido e complexo das autorrepresentações indígenas no audiovisual (KASEKER, 2019).

Outro ponto da presença e da visibilidade indígena nas redes sociais durante a crise do novo coronavírus é percebido na atuação da advogada e deputada federal Joênia Wapichana (Rede Sustentabilidade). Joênia, da etnia Wapichana, é a primeira mulher indígena a exercer o cargo de deputada federal no Brasil (FUNAI, 2018) e atua junto à Frente Parlamentar Indígena, no Congresso Nacional. As redes sociais da deputada, eleita em 2018, servem para mostrar o trabalho da parlamentar sobre a temática indígena, principal bandeira levantada pela deputada durante campanha eleitoral. Mas muito além de divulgar o trabalho da deputada, o perfil de Joênia nas redes sociais também é de cunho autorrepresentativo, informativo e denunciativo.

Em uma reportagem ao HuffPost, publicada no dia 5 de maio de 2020, a deputada afirmou que "os povos indígenas estão vulneráveis e não têm proteção" (POVOS, 2020). Nas redes sociais, a deputada expôs os esforços da Frente Parlamentar Indígena de contribuir com ações no âmbito do poder público para o enfrentamento e proteção dos povos indígenas em meio à pandemia da Covid-19.

\section{Considerações finais}

Ao longo da história, as epidemias dizimaram as populações indígenas na América Latina, e o drama vivenciado por toda a sociedade brasileira em momentos como a pandemia da Covid-19 não é novidade para os povos originários. Desta vez, porém, o movimento indígena ocupou as telas para se prevenir do contágio e para se defender do descaso 


\section{RIF, Ponta Grossa/PR Volume 18, Número 40, p.183-198, Janeiro/Junho 2020}

governamental em relação à saúde das comunidades. E fez isso convidando os indígenas, por meio das câmeras de celular e acesso - mesmo que precário - à internet via dados móveis, a gravarem suas próprias campanhas de orientação e disseminarem em suas redes sociais. Também foi assim que assistiram palestras, participaram de rodas de conversa sobre saúde em salas virtuais e se mobilizaram no primeiro Acampamento Terra Livre realizado online, com lives nas redes sociais.

A autorrepresentação indígena por meio do audiovisual na internet é um fenômeno recente. Percebe-se que o uso de dispositivos móveis e aplicativos como o WhatsApp, Facebook e plataformas como o YouTube impulsionaram este movimento. Na observação assistemática do movimento indígena, ao seguir grupos como a Apib, a Rádio Yandê e a página Mídia Índia, além de estudantes universitários indígenas e lideranças, é difícil até mesmo realizar um mapeamento dessas produções, devido à sua abundância. Um dos importantes usos do audiovisual pelas comunidades tem sido para sua própria segurança e vigilância nas áreas de conflito. Os indígenas estão com a câmera na mão, lutando pela demarcação de seus territórios, mas estão também com seus celulares na mão para se prevenirem da Covid-19.

As comunidades se conectaram e ocuparam as redes, para denunciar as violações aos seus direitos e o descaso dos poderes públicos principalmente nesse período. Demarcaram as telas, um novo espaço de existência e de sobrevivência das comunidades, lugar onde conectaram e expandiram seus territórios para a dimensão virtual. O movimento de autorrepresentação indígena utilizando o audiovisual nas mídias sociais corrobora com a visão de que a cultura é um processo vivo e dinâmico. A atualização de suas identidades étnicas e tradicionais neste quesito tornou-se uma questão de sobrevivência. As linguagens midiáticas como o audiovisual, as plataformas digitais e a própria internet ajudam a fortalecer sua cultura e suas diferenças, mas também a expor e denunciar as diversas violações ao direito de existência dos povos tradicionais e busca combater desigualdades.

Importante ressaltar que essas considerações são provisórias, pois até o fechamento deste artigo a pandemia ainda estava em pleno andamento. Até o dia 7 de maio de 2020, os números de indígenas contaminados pela Covid-19 na Amazônia brasileira, região mais afetada, eram: 123 casos suspeitos, 177 casos confirmados e 49 óbitos (APIB, 2020). A proposta é continuar observando como a situação de vulnerabilidade das populações 
indígenas se desdobrará, assim como as ações de prevenção e de denúncia por parte do movimento indígena nas redes sociais.

\section{Referências}

APIB - ARTICULAÇÃO DOS POVOS INDÍGENAS DO BRASIL. Informativo COIAB. Disponível em: https://www.instagram.com/p/B_8VvrCnKSA/?utm_source=ig_web_copy_link. Acesso em: 8 maio 2020.

ARAÚJO, Juliano José de. Cineastas indígenas, documentário e autoetnografia: um estudo do projeto Vídeo nas Aldeias. 2015. 270f. Tese (Doutorado em Multimeios) - Instituto de Artes da Unicamp. Universidade Estadual de Campinas, Campinas.

BITTENCOURT, Maurício Pimentel Homem de. Diálogo parcial - uma análise da cobertura da imprensa para a questão indígena brasileira. In: 29 CONGRESSO BRASILEIRO DE CIÊNCIAS DA COMUNICAÇÃO - INTERCOM, 2006, Brasília. Anais eletrônicos... São Paulo: Intercom, 2006. Disponível em: http://www.intercom.org.br/papers/nacionais/2006/resumos/R2180-1.pdf. Acesso em: 14 mar. 2019.

BLECHER, Bruno. Brasil usou arma biológica contra índios. Folha de S. Paulo. São Paulo, 28 out. 2001. Disponível em: https://www1.folha.uol.com.br/fsp/mundo/ft2810200104.htm. Acesso em: 21 mar. 2020.

CANEVACCI, Massimo. Autorrepresentação: movimentar epistemologias no contexto da cultura digital e da metrópole comunicacional. Revista Novos Olhares, v. 4, n.1, p. 16-20, 2015 Disponível em: http://www.revistas.usp.br/novosolhares/article/view/102237. Acesso em: 28 abr. 2020.

CODEÇO, Claudia Torres et. al. Estimativa de risco de espalhamento da COVID-19 no Brasil e avaliação da vulnerabilidade socioeconômica nas microrregiões brasileiras. Disponível em: https://bibliotecadigital.fgv.br/dspace/handle/10438/28942. Acesso em: 6 maio 2020.

CONTAMINAÇÃO de indígenas pela Covid-19 avança no Amazonas. Diário do Nordeste. Fortaleza, 42020.2 maio 4 em: https://diariodonordeste.verdesmares.com.br/editorias/pais/contaminacao-de-indigenaspela-covid-19-avanca-no-amazonas-1.2242068. Acesso em: 4 maio 2020.

DI FELICE, Massimo; PEREIRA, Eliete (org.). Redes e ecologias comunicativas: as contribuições dos povos originários à Teoria da Comunicação. São Paulo: Paulus, 2017.

FELLET, João. Em meio à Covid-19, garimpo avança e se aproxima de índios isolados em Roraima. BBC Brasil. São Paulo, 9 abr. 2020. Disponível em: https://www.bbc.com/portuguese/brasil-52225713. Acesso em: 5 maio 2020.

FONTES, Mariana; THENÓRIO, Iberê. Yanomamis brasileiros e venezuelanos cortam relações por causa da nova gripe. Portal G1. São Paulo, 5 nov. 2009. Disponível em: 
http://g1.globo.com/Amazonia/0,,MUL1367414-16052,00-

YANOMAMIS+BRASILEIROS+E+VENEZUELANOS+CORTAM+RELACOES+POR+CAUSA+DA+NOVA +GRIP.html. Acesso em: 21 mar. 2020.

FUNAI - FUNDAÇÃO NACIONAL DO ÍNDIO. Funai entrevista Joênia Wapichana - a primeira mulher indígena a ser eleita deputada federal no Brasil. Funai - Fundação Nacional do Índio.

Brasília, 8 out. 8018.2 Disponível em: http://www.funai.gov.br/index.php/comunicacao/noticias/5065-funai-entrevista-joeniawapixana-a-primeira-mulher-indigena-a-ser-eleita-deputada-federal-no-brasil. Acesso em: 5 maio 2020.

IBGE - INSTItUTO BRASILEIRO DE GEOgRAfiA E ESTAtísticA. Censo Demográfico Populacional, 2010. Disponível em: https://censo2010.ibge.gov.br/. Acesso em: 25 abr. 2020.

INSTITUTO SOCIOAMBIENTAL. COVID-19 e os povos indígenas. Disponível em: https://covid19.socioambiental.org/. Acesso em: 3 maio 2020.

KASEKER, Mônica Panis. Identidades híbridas e imagens complexas: a autorrepresentação indígena na web. Artigo apresentado no Eixo Temático 2 - Cultura Digital do VII Encontro Nacional de Estudos da Imagem. IV Encontro Internacional de Estudos da Imagem, realizado de 14 a 17 de maio de 2019, na Universidade Estadual de Londrina.

KOPENAWA, Davi; ALBERT, Bruce. A queda do céu: palavras de um Xamã Yanomami. São Paulo: Companhia das Letras, 2015.

KRENAK, Ailton. Ideias para adiar o fim do mundo. Rio de Janeiro: Companhia das Letras, 2019.

KRENAK, Ailton. O amanhã não está à venda. Rio de Janeiro: Companhia das Letras, 2020.

LIMA, Luciana S. Por um retrato dos invisíveis - Imagens Do Povo Guarani Kaiowá. Dissertação (Mestrado em Comunicação) - Universidade Federal do Rio de Janeiro, 2012. Disponível em: http://www.pos.eco.ufrj.br/site/teses_dissertacoes_interna.php?dissertacao=2. Acesso em: 2 abr. 2019.

OLIVEIRA, João Pacheco de; FREIRE, Carlos Augusto da Rocha. A presença indígena na formação do Brasil. Brasília: Ministério da Educação, Secretaria de Educação Continuada, Alfabetização e Diversidade; LACED/Museu Nacional, 2006.

OLIVEIRA, Ubirajara et. al. Modelagem da vulnerabilidade dos povos indígenas no Brasil ao covid-19. Disponível em: https://www.socioambiental.org/sites/blog.socioambiental.org/files/nsa/arquivos/nota_tecni ca_modelo_covid19.pdf. Acesso em: 6 maio 2020.

POVOS indígenas do Brasil pedem fundo de emergência à OMS para combater coronavírus. HuffPost. São Paulo, 5 maio 2020. Disponível em: https://www.huffpostbrasil.com/entry/indigenas- 


\section{RIF, Ponta Grossa/PR Volume 18, Número 40, p.183-198, Janeiro/Junho 2020}

coronavirus_br_5eb18be2c5b6a15b6f46b0d0?ncid=NEWSSTAND0004\&guccounter=1\&guce_r eferrer=aHROcHM6Ly93d3cuZ29vZ2xILmNvbS8\&guce_referrer_sig=AQAAAKrSodn3DX0TWOO6SnIAbjv20y5IPZGRagZNO_I1-

1SubDJfyLhX1pmT312sXXjxmzNZXxvzKxuaKCqTOtIWXZU9aXivT7SNnQ38KZ3o3e_UxLxIEcllvbR S_oCXOPG2dnoo5HFQ3WXt|xJ3d-ga_AnLu5SD6GC8dlBcxuwMMbX. Acesso em: 5 maio 2020.

RIBEIRO, Lucas Fernando; KASEKER, Mônica Panis. A experiência da Webradio Yandê como etnomídia em um contexto de convergência midiática. In: 41ㅇ CONGRESSO BRASILEIRO DE CIÊNCIAS DA COMUNICAÇÃO - INTERCOM 2018, Joinville. Anais eletrônicos... São Paulo: Intercom, $2018 . \quad$ Disponível em: http://portalintercom.org.br/anais/nacional2018/resumos/R13-1554-1.pdf. Acesso em: 30 abr. 2020.

RIBEIRO, Lucas; KASEKER, Mônica. Autobiografias Étnico-Comunitárias: o audiovisual como articulador de sentidos de identidade e interculturalidade. In: 42 CONGRESSO BRASILEIRO DE CIÊNCIAS DA COMUNICAÇÃO - INTERCOM 2019, Belém. Anais eletrônicos... São Paulo: Intercom, 2019.2 Disponível em: http://portalintercom.org.br/anais/nacional2019/resumos/R14-0719-1.pdf. Acesso em: 30 abr. 2020.

TUPINAMBÁ MACHADO, Renata. Yandê, etnomídia indígena e educação. Revista Cátedra Digital. Vol.4. № 5 Tema: Literatura infantil e juvenil de etnias indígenas brasileiras. S/D Acesso em 27 mai. 2020. 